\title{
O PRINCÍPIO DA INSIGNIFICÂNCIA E OS CRIMES CONTRA A ORDEM TRIBUTÁRIA
}

\author{
THE PRINCIPLE OF INSIGNIFICANCE IN CRIMES AGAINST THE TAX LAW
}

\section{Luiz Gonzaga Goulart Rodrigues*}

\begin{abstract}
Resumo:
O Princípio da Insignificância, que dirige-se ao Magistrado, decorre do Princípio da Intervenção Mínima do Estado, que dirige-se ao Legislador. Não se trata de uma espécie do gênero Teoria da Adequação Social, quando a conduta não é tipificada, dada a sua aceitação social. Numa conduta ilícita que preencha formal e materialmente o tipo penal, caberá ao Magistrado o recurso de interpretação restritiva, tornando a conduta atípica, quando for ínfima a lesão ao bem jurídico protegido. A fundamentação da atipicidade é dada pelo Princípio da Insignificância. Dado ser um Princípio não-positivado, é errônea a fundamentação do magistrado da sua aplicação quando existe previsão legal em norma estatuída, para valores nãomerecedores da dignidade penal, por sua Insignificância, como ocorre no Direito Tributário. Nesses casos, vai ocorrer o mero atendimento ao normatizado. A sua aplicabilidade a despeito da não-previsão legislativa não acarreta insegurança jurídica, dada a lesão ínfima.
\end{abstract}

Palavras-chave: Princípio da Insignificância. Bagatela. Ilícito. Direito Tributário.

\begin{abstract}
:
The Principle of Insignificance, which addresses the Magistrate derives from the Principle of Minimum Intervention of the State, which is addressed to the legislator. This is not a species of the genus Theory of Social Adjustment, when the conduct is not typed, given its social acceptance. In a wrongful conduct that meets formally and materially the offense, it will be up to the magistrate feature restrictive interpretation, making the atypical behavior, where the slightest injury to legally protected. The atypicality is given by the Principle of Insignificance. Having no legal provision, becomes the erroneous reasoning of the magistrate's application when there is legal provision establishing values for non-criminal deserving of dignity, as in Tax Law. In such cases, will occur mere standardized service. Its applicability in spite of nonlegislative forecast does not entail legal uncertainty, given the slightest injury.
\end{abstract}

Keywords: Insignificance.Crimes. Tax Law.

\section{Introdução}

O Princípio da Insignificância já se explica pela sua própria denominação: há fatos in concreto que, a despeito de atenderem todas as condições de antijuridicidade e culpabilidade, dada a mínima ou nenhuma lesão a bem jurídico tutelado, não possuem

Médico. Bacharel em Direito pela Faculdade de Direito da Universidade de São Paulo. 
dignidade penal para que o Estado mova todo o aparato jurisdicional para aplicar o ius puniendi, sendo que a pena aplicada, proporcional e razoável, não cumprirá sua finalidade de ressocialização. Torna o fato atípico.

É uma criação doutrinária e de aplicação jurisprudencial que leva em conta as fontes do Direito, princípios gerais do Direito, princípios constitucionais, a evolução histórica do Direito Penal, bem como a Política Criminal.

Apenas o nosso Código Penal Militar faz a sua previsão objetiva, em sua Parte Especial, Livro I, Dos Crimes militares em tempos de Paz, Título V, Dos crimes contra o Patrimônio, Capítulo I, Do Furto, artigo 240:

Subtrair, para si ou para outrem, coisa alheia móvel:

Pena - reclusão, até seis anos.

$\S 1^{\circ}$ - Se o agente é primário e é de pequeno valor a coisa furtada, o juiz pode substituir a pena de reclusão pela de detenção, diminuí-la de um a dois terços, ou considerar a infração como disciplinar.

Entende-se pequeno o valor que não exceda a um décimo da quantia mensal do mais alto salário mínimo do país.

Pode-se depreender que o Legislador levou em consideração o Princípio da Intervenção Mínima do Estado ao estabelecer um valor mínimo para que o este possa praticar o seu ius puniendi. Nesses casos não se pode atribuir a atipicidade ao uso discricionário interpretativo restritivo do Magistrado, mas apenas a observância do estatuído pela norma. Princípios, muito embora rejam todo o ordenamento jurídico não são positivados, sendo a sua observância meramente deduzida.

Por essa razão, para o estudo do Princípio da Insignificância será necessário discorrer sobre esses temas para finalmente poder-se chegar ao seu entendimento e aplicação. Por não ser norma legal estatuída positivamente, mas um recurso de interpretação restritiva, a sua aplicação é feita diretamente pelo juiz, em casos concretos, daí a necessidade da apresentação da fundamentação das sentenças em julgados e a jurisprudência. Por fim, a apresentação de julgados no âmbito do Direito Tributário, com aplicação ou não do Princípio da Insignificância, razão de ser desse trabalho.

\section{O Princípio da Insignificância}

O Princípio da Insignificância ou Bagatela foi elaborado por Claus Roxin ${ }^{1}$ em 1964, como decorrência da retomada do brocardo minima non curat praetor. Propôs a introdução de um princípio que pudesse ser auxiliarmente utilizado como recurso para a interpretação restritiva da tipificação dos delitos penais, tendo em vista a necessidade

$1 \quad$ ROXIN, Claus. Política criminal y sistema del derecho penal. Trad. Francisco Muñoz Conde y Eugenio R Zaffaroni. 2. ed. Buenos Aires: Editorial Hammurabi, 2002. 
de haver uma valoração adequada da tipificação material do ilícito in concreto, buscandose que a punibilidade somente ocorra quando indispensável para a proteção de um bem jurídico efetiva e relevantemente violado. Por meio da utilização do Princípio da Insignificância os danos de pouca importância devem resultar em uma valoração de atipicidade material, afastando a punibilidade.

A aplicação do Princípio da Insignificância deve ocorrer juntamente com o Princípio da Proporcionalidade da pena em relação à gravidade do injusto e os Princípios constitucionais limitadores do poder estatal, como o Princípio da Intervenção Mínima, tutelando os bens jurídicos mais relevantes, e o Princípio da Fragmentariedade, atuando o Direito Penal apenas quando a tutela não possa ser realizada pelos demais ramos do Direito.

O Princípio da Insignificância está relacionado com a infração bagatelar, que vem a ser aquela cometida com efetiva lesão ao bem jurídico tutelado que, porém é de tão pequena monta, em qualidade ou quantidade, que não requer ou não tem dignidade penal, a ponto de mover a tutela jurisdicional do Estado, em seu ius puniendi. A doutrina tem estabelecido que a infração bagatelar pode ter duas dimensões:

Infração bagatelar própria: o delito já nasce sem relevância penal, sem significância. Seja porque não há desvalor na ação, não há periculosidade na conduta e a idoneidade ofensiva é irrelevante. Ou ainda porque não há relevância no resultado, não sendo considerado um ataque ou lesão significativa do bem jurídico tutelado. Há insignificância na conduta e no resultado. $\mathrm{O}$ fato já nasce, de per si, insignificante. Nesses casos, diante de uma interpretação restritiva do juiz, afastase a tipicidade material do delito, descaracterizando assim a tipicidade e, consequentemente a sua punibilidade. Torna-se um fato atípico e não há incidência do Direito Penal. Não a nem mesmo a instauração de processo contra o agente.

Infração bagatelar imprópria: ocorrência do delito típico, com dignidade penal, havendo relevante desvalor da conduta e também desvalor do resultado. Posteriormente se verifica que a aplicação de qualquer pena se torna desnecessária pelo Princípio da Irrelevância penal do fato, aplicando-se assim o Princípio da desnecessidade da pena. A não aplicação de pena vai resultar da interpretação, observância e aplicação de diversos fatores: reparação dos danos, reconhecimento da culpa, colaboração com a justiça e outros fatores. Por ser um Princípio interpretativo, ocorrerá também no momento da quantificação da pena, a aplicação dos elementos do artigo 59 do Código Penal. Há a instauração do processo e a 
dispensa da pena faz-se semelhante ao que ocorre no perdão judicial. $^{2}$

Tem ocorrido em julgados a fundamentação interpretativa para a sentença da ocorrência de Infração Bagatelar Imprópria, como nos casos de peculato culposo. O agente do delito faz a reparação dos danos (circunstância postfactum) anteriormente à aplicação da sentença, extinguindo a punibilidade e tornando a pena desnecessária. Inicialmente havia a ocorrência do desvalor da ação e do resultado. A reparação dos danos torna a pena desnecessária. Também em casos de crimes tributários, cujo pagamento dos tributos acarreta o perdão judicial. A Delação Premiada também acaba por se tornar a aplicação da Infração Bagatelar Imprópria, já que a colaboração na elucidação de outros delitos na defesa de bem jurídico ser considerado mais relevante do que a lesão de pequena monta cometida pelo agente.

Como se verá adiante, a doutrina majoritariamente não aceita a aplicação do art. 59 do Código Penal como elemento para a aplicação do princípio da Insignificância, posto que valorar antecedentes criminais do agente, conduta, crimes anteriores, penas aplicadas e etc., viria a se tornar a aplicação de um Direito Penal do Autor, o que se apresenta como um retrocesso, tendo em vista que o Estado Democrático de Direito de há muito já aplica o Direito Penal do fato em si, do delito e não mais do autor ou agente.

$\mathrm{Na}$ apresentação dos julgados onde se aplica a Princípio da Insignificância também será apresentada a visão doutrinária contrária a sua aplicação, fundamentando que seria um desvalor de todo o Direito Penal, a incitação à reincidência e criminalidade pela impunidade e a concordância estatal com a utilização de crimes de pequena monta como meio de vida.

Por outro lado, como também se verá, torna-se um erro a fundamentação da aplicação do Princípio da Insignificância, quando o Direito legislado tem previsão para o delito, como os que ocorrem em valores inferiores a uma norma legal estatuída, como no Direito Tributário. Nesses casos não se trata da aplicação do Princípio da Insignificância, mas a mera aplicação de uma norma que já estabelece aqueles valores como insignificantes ou não merecedores de dignidade penal.

\section{Evolução histórica}

O Princípio da Legalidade tem seu início na obra Dei delitti e delle pene, de Cesare Beccaria, ${ }^{3}$ de 1764: apenas as leis podem fixar penas com relação aos delitos praticados. Esta autoridade não pode residir senão na pessoa do Legislador, que representa toda a sociedade, agrupada por um contrato social. Afirma ainda, o que viria a

2 GOMES, LUIZ Flávio. Norma e bem jurídico no direito penal. São Paulo: Revista dos Tribunais, 2002. BECCARIA, Cesare. Dos delitos e das penas. São Paulo: Ed. Hemus, 1983. 
dar o fundamento jurídico do Princípio da Insignificância: a exata medida dos crimes é o prejuízo causado à sociedade.

A partir de então caberá ao Estado a elaboração de leis escritas, por meio do Poder Legislativo, representando os valores sociais da época e as condutas a serem reprimidas. Essa premissa de Reserva Legal ao Estado fundamentou o período de Codificação em todo o mundo ocidental a partir de então, principiando com a Declaração de Virgínia, de 1776: nenhum homem será privado de sua liberdade, exceto pela lei do país ou o julgamento dos seus pares. A Déclaration dês Droits de l'Homme et du Citoyen, de 1789: nenhum homem pode ser acusado, detido ou encarcerado, senão nos casos determinados pela lei e segundo as formas por ela exigidas.

Ao período de Constitucionalismo seguiu-se o Positivismo jurídico, com uma construção dogmática que restringia quase que completamente a interpretação legal, sendo que o juiz estava adstrito ao preceito legal. Na Dogmática clássica não se aceitam raciocínios valorativos dado que são subjetivos e, portanto, indemonstráveis. A metodologia aplicada é a dedutiva, partindo-se dos textos legais abstratos para adequálos aos casos in concreto. A segurança jurídica baseava-se na neutralidade axiológica, em busca da segurança jurídica.

Conforme citado por Roxin, em Política criminal y sistema del derecho penal, foi Liszt quem estabeleceu uma metodologia jurídico-científica para o Direito Penal como uma ciência autônoma, que deve ser considerada isoladamente da Política Criminal. Afirma Liszt: el Derecho Penal es la infranqueble barrera de la Política Criminal. Propõe que a dogmática penal tenha como objeto de estudo os textos legais abstratamente, não vinculado aos fatos in concreto. A título de exemplo, na Literatura da época, final do século XIX, na obra de Vitor Hugo, ${ }^{4}$ o romance Les Miserables relata a vida de Jean Valjean, condenado pelo furto de alguns pães para alimentar a família. Após constantes fugas da prisão, será perseguido pelo Inspetor Javert, representando o poder punitivo penal do Estado. Conforme vigente à época, a mera e simples aplicação legal do brocardo dura lex sed lex. Refere-se a um momento histórico de implantação de um Direito positivado e da Ciência do Direito Penal se firmando como uma ciência autônoma, cujo objeto próprio de estudo é o delito e o juiz subsume-se estritamente à norma positivada, alheia á Política Criminal. Não é outra a razão que levou Ruy Barbosa, em seu imortal discurso "Oração aos moços", a aconselhar aqueles que, porventura, escolhessem a carreira de Magistrados: ... não anteponhais o draconianismo à equidade. Dados a tão cruel mania, ganharíeis, com razão, conceito de maus, não de retos. ${ }^{5}$ GILIOLI

Claus Roxin, em Política Criminal y sistema del derecho penal fundamenta que o fim do Direito Penal deve ser a consecução da Política Criminal. Assim, permanece

$4 \quad$ VITOR HUGO. Os miseráveis. São Paulo: Ed. Clube do Livro, 1958.

5 GILIOLI, Adolfo Lemes. Academia e discursos acadêmicos. São Paulo: Ed. Martin Claret, 2001. 
o Positivismo Jurídico em sine lege praevia, com o Princípio da Legalidade seguido pelo Legislador. Porém, o nullum crimen contém preceitos da Política Criminal que estabelecem um fim para o Direito Penal. Dessa maneira, a sistematização das elaborações lógicodogmáticas conceituais deve passar pela valoração Político-criminal do caso in concreto.

Essa visão funcionalista sistêmica modernamente aceita pela doutrina vai frontalmente em direção oposta à da Teoria Pura do Direito, onde Hans Kelsen ${ }^{6}$ pretende “... desenvolver uma teoria jurídica pura, isto é, purificada de toda ideologia política e de todos os elementos de ciência natural, consciente da sua especificidade porque consciente da legalidade específica do seu objeto". Por essa visão, o Direito como fim em si mesmo. E não o Direito como sendo um realizador da Política Criminal.

Diferentemente, Miguel Reale ${ }^{7}$ ensina a Teoria Tridimensional do Direito, com "o fato, o valor e a norma". A norma remete ao poder punitivo estatal com o sine praevia lege; o valor representa a somatória dos valores aceitos socialmente e endereçada ao Legislador para que o Estado a cumpra como Política Criminal estabelecendo o que para ela é o nullum crime. $\mathrm{O}$ fato é o fato in concreto, vivências sociais às quais o Direito não pode estar alheio e, dentre elas, estabelecer o que é indiferente e o que merece tutela punitiva penal estatal.

Sob essa nova sistematização, o magistrado deveria restringir o uso de penas excessivas, acolhendo o brocardo minima non curat praetor. O Direito Penal deveria se ocupar de questões de interesse realmente relevantes e não de insignificâncias. A Política Criminal corresponde à missão social do Direito Penal, enquanto que o seu sentido jurídico deve corresponder à função do Estado de Direito, assegurando a igualdade de todos na aplicação das leis e defendendo a liberdade individual, inclusive contra o Poder Estatal. Dessa maneira, a finalidade do Direito Penal é o cumprimento da Política Criminal.

O estudo e a aplicação do Direito Penal devem ser feitos de maneira a considerar e valorar sistematicamente todo o ordenamento jurídico diante de um caso in concreto, não se atendo exclusivamente à tipificação legislada. Sem o que, conforme Welzel, ${ }^{8}$ também citado por Roxin: “... como ciencia sistemática da la base para uma Administración de Justicia uniforme e justa, pues solo el conocimiento de las relaciones internas del Derecho eleva su aplicación por encima del acaso y la arbitrariedad".

Em sendo o Direito Penal uma ciência com dupla seara, Social e Jurídica, as soluções de problemas jurídicos devem atender tanto o aspecto da significação dos conceitos sistemáticos gerais e das abstrações dogmáticas, porém sempre atentando, no fato in concreto, para os ditames da Política Criminal, que deve ser prioritária com o fim

6 KELSEN, Hans. Teoria pura do direito. Trad. João Baptista Machado. 6. ed. São Paulo: Martins Fontes, 2005.

7 REALE, Miguel. Lições preliminares de direito. 25. ed. São Paulo: Saravia, 2000.

8 WELZEL, Hans. Derecho penal alemã. Trad. Juan Bustos Ramírez e Sérgio Yáñez Pérez. 11. ed. Santiago: Ed. Jurídica, 1970. 
de realizar a justiça social. Os valores sociais contidos na Política Criminal poder-se-ia dizer que corrigem as abstrações dogmática-conceituais para um delito considerado e o fato concreto, ocorrido na vida real.

Jescheck, em citação de Roxin, sobre o pensamento sistemático, conclui: "no debe desconecerse, sin embargo, el peligro de uma dogmática jurídico-penal basada em fórmulas abstractas: este radica em que el juez se abandona al automatismo de los conceptos teóricos, olvidando así las particularidades del caso concreto. Lo decisivo há de ser siempre la solución de la cuestión de hecho, mientras que las exigências sistemáticas deben ocupar el segundo plano".

Por essa metodologia jurídico-penal conclui-se que um Estado de Direito que garanta as liberdades individuais, tipificando condutas criminalmente, deve considerar também o Estado Social por sua Política Criminal, estabelecendo um Estado Democrático de Direito, como consagra a Constituição brasileira de 1988. As categorias componentes do delito - tipicidade e culpabilidade - que representam o poder punitivo estatal, contido na expressão sine lege praevia devem ser consideradas em sua interpretação de casos in concreto de todo o ordenamento jurídico, em função da realização da Política Criminal, que vem a ser o nullum crimen, somatória de valores aceitos por uma determinada comunidade em certo tempo. São esses valores sociais contidos na Política Criminal que vão determinar o que vem a ser considerado antijurídico assim como a aplicação de sanções, cujas penas devem cumprir uma função ressocializadora e não mais retributiva por descumprimento de preceitos penais estatais.

Com a finalidade de fazer com que a Política Criminal seja realmente uma barreira intransponível ao Direito Penal, Welzel introduz a Teoria da Adequação Social, um auxiliar interpretativo restritivo ao magistrado, para formas de conduta socialmente admissíveis. Por meio da sua aplicação torna atípicas as condutas como lesão corporal eventualmente ocorrida na prática desportiva, na atuação médica (cirurgias) ou ainda em costumes, como a circuncisão. Regis Prado ${ }^{9}$ cita o jurista espanhol, Mir Puig, que indaga: pode o Estado reprimir uma conduta que a sociedade não condena? A Teoria da Adequação Social faz por colocar em evidência que o Direito Penal é um meio para a consecução da Política Criminal e nunca o seu contrário. Condutas aceitas pelo conjunto social não podem ser criminalizadas pelo Legislador.

Nessa esteira, Claus Roxin introduz o Princípio da Insignificância, também um outro auxiliar interpretativo restritivo, a ser utilizado pelo magistrado, em casos concretos. Não se trata de uma espécie do gênero Teoria da Adequação social, posto que a conduta atende ao tipo formalmente em seu aspecto formal e material. Não abrange também os casos de adequação social, pois o fato concreto é reconhecidamente típico,

$9 \quad$ PRADO, Luiz Regis. Curso de direito penal brasileira: parte geral. 5. ed. São Paulo: Revista dos Tribunais, 2005. v. 1. 
formal e materialmente. Apenas que, em seu aspecto material, há lesão irrelevante do bem jurídico protegido, não atingindo dignidade penal para que se mova todo o aparato jurisdicional estatal pela sua insignificância. Nesses casos, a pena imposta, atendendo ao princípio da proporcionalidade e também da razoabilidade é incompatível com o seu fim ressocializante. Assim, o Magistrado, reconhecendo a tipicidade formal e material do fato concreto, pela irrelevância ou nula lesão ao bem jurídico considerado, torna o fato atípico.

Nas palavras do próprio Claus Roxin, em tradução de Francisco M. Conde: "el llamado principio de la insignificancia, que permite en la mayoria de los tipos excluir desde um principio daños de poca importancia: maltrato no es cualquier tipo de dano de la integridad corporal, sino solamente uno relevante; analogamente deshonesto en el sentido del Código Penal es sólo la acción sexual de cierta importância; injuriosa es uma forma delictiva es sólo la lesion grave a la pretensión social de respeto. Como "fuerza" debe considerarse unicamente un obstáculo de cierta importância, igualmente también la amenaza debe ser "sensible" para pasar ele umbral de la criminalidad. Si com estos planteamientos se organizara de nuevo consecuentemente la instrumentación de nuestra interpretación de tipo, se lograria, ademas de uma mejor interpretación".

Em conformidade com a Política Criminal decorrente da Constituição brasileira de 1988, que estabelece o Estado Democrático de Direito e que erige a dignidade humana como princípio basilar e diretivo, apresentam-se a seguir os princípios fundamentais do Direito Penal envolvidos na aplicação do Princípio da Insignificância.

\section{Princípios fundamentais do Direito Penal}

Princípio é um mandamento nuclear e essencial, sustentáculo de um sistema. Sua violação implica a negação de todo o sistema e subverte os seus valores fundamentais. Diferentemente do Direito Penal que possui normas positivadas, a Política Criminal não se perfaz em um documento codificado, mas constitui-se de princípios basilares dos valores sociais aceitos em determinado momento histórico daquela comunidade. E será essa Política Criminal, com seus valores e princípios, quem ditará ao Legislador aquilo que deseja que seja tipificado como ilícito, por ser lesivo aos bens jurídicos considerados relevantes e a serem protegidos.

Os valores constitucionais possuem as facetas fundamentadora, orientadora e crítica. É fundamentadora do conjunto de disposições e instituições constitucionais e do ordenamento jurídico como um todo, constituindo o núcleo basilar e informador do sistema jurídico-político. A dimensão orientadora em relação aos fins e metas da 
ordem político-jurídica. Crítica por ser critério e paradigma para a valoração de fatos ou condutas. ${ }^{10}$

\section{Princípio da Legalidade}

Também recebe a denominação de Princípio da Reserva legal, da legalidade dos delitos e das penas ou da intervenção legalizada. Fundamenta o art. $1^{\mathrm{o}}$ do Código Penal e tem sua base constitucional no art. 5 XXXIX da Constituição Federal de 1988.

Em sentido amplo, estabelece que não há crime ou infração penal, nem pena ou medida de segurança, representando sanções penais, sem prévia lei. A criação dos tipos delituais e suas conseqüências jurídicas estão submetidos à lei formal.

Origina-se na obra Dei delitti e delle pene, de ${ }^{3}$ Cesare Beccaria, ${ }^{11}$ de 1764 e representa a base de todo o Estado de Direito, iniciado com a Revolução Francesa, com a Declaração dos Direitos do Homem e do Cidadão. Representa a segurança jurídica e a garantia dos direitos individuais diante da intervenção punitiva do Estado.

\section{Princípio da Dignidade Humana}

Em Dei delitti e delle penne, Becarria afirma: não existe liberdade onde as leis permitem que, em determinadas circunstâncias, o homem deixe de ser pessoa e se converta em coisa.

A Dignidade Humana e o conceito de pessoa humana possuem validade a priori, antecedendo o juízo axiológico do Legislador e vincula de forma absoluta a sua atividade, em especial no Direito Penal. Não é, portanto uma criação legislativa, tendo sido positivada na Constituição Brasileira de 1988 como um valor básico, postulado fundamental. ${ }^{12}$ Em seu art. $1^{\circ}$, III estabelece a Dignidade Humana como valor fundamentador dos direitos fundamentais da pessoa humana.

A força normativa do princípio máximo da Dignidade da Pessoa Humana se imiscui em toda a ordem jurídica e serve de alicerce a todos os princípios penais fundamentais. Qualquer transgressão a qualquer um desses princípios, em última análise, constituir-se-á em lesão ao Princípio da Dignidade Humana.

10 PÉREZ LUÑO, A. E. Derechos humanos, estado de derecho y constituición. 1. ed Madrid: Ed. Tecnos, 1990.

11 BECCARIA, Cesare. Dos delitos e das penas. São Paulo: Ed. Hemus, 1983.

12 PRADO, Luiz Regis. Curso de direito penal brasileira: parte geral. 5. ed. São Paulo: Revista dos Tribunais, 2005. v. 1. 
III. Princípio da irretroatividade

O Direito Penal tecnicamente deve elaborar leis formais, claras e precisas, conforme o Princípio da Legalidade e, mais, que a lei penal nunca poderá ser retroativa, ressalvando-se a retroatividade favorável ao acusado. Do art. $5^{\circ}, \mathrm{XL}$, da Constituição e art. $2^{\circ}$ do Código Penal: a lei penal não retroagirá, salvo para beneficiar o réu.

\section{Princípio da Taxatividade}

Dá orientação técnica à elaboração das leis penais, determinando que sejam claras e precisas na formulação do tipo legal e suas consequências jurídicas, como a sanção penal. Essa taxatividade apresenta-se como uma função garantista, constituindo limitação ao poder punitivo estatal e garantia de igualdade de tratamento. Como decorrência do Princípio da Taxatividade, ao Direito Penal é defeso o uso da Analogia ou dos Usos e Costumes. $\mathrm{O}$ fato in concreto deve atender a tipificação legal em todos os seus elementos constitutivos ou então deverá ser tido como atípico.

\section{Princípio da Culpabilidade}

Nulla poena sine culpa. Sem a culpabilidade não há pena e esta não deve ultrapassar a medida da culpabilidade, em proporcionalidade e razoabilidade. A culpabilidade é o fundamento e o limite de toda pena. Segundo esse Princípio, o Direito Penal só pode punir fatos, como um Direito Penal do Fato e nunca a culpabilidade ser fundada no modo de vida ou no caráter do agente, o que se constitui em Direito Penal do Autor.

VI. Princípio da exclusiva proteção de bens jurídicos

O escopo principal do Direito Penal é a proteção de bens jurídicos, decorrente da concepção de Estado de Direito democrático. Não há delito sem que haja lesão ou perigo de lesão a um bem jurídico específico. Dessa maneira, a tutela penal só se torna legítima quando socialmente necessária.

O conceito de bem jurídico é necessariamente valorado e relativo por uma comunidade social, em determinado momento histórico e cultural.

O bem jurídico tem algumas funções:

A - função de garantia

Como elemento basilar da Política Criminal restringe o ius puniendi estatal na elaboração dos tipos penais.

B - função teleológica 
Critério interpretativo dos tipos penais, condicionando seu alcance e sentido, na finalidade de proteção de determinado bem jurídico.

$\mathrm{C}$ - função individualizadora

Como critério de medida da pena no momento da sua determinação, levando sempre em conta a gravidade da lesão ao bem jurídico, como desvalor de resultado.

D - função sistemática

Como elemento classificatório dos grupos de tipos, por bem jurídico considerado. ${ }^{7} \mathrm{PRADO}$

\section{Princípio da Intervenção Mínima}

Também denominado de Princípio da Subsidiariedade, estabelece que o Direito Penal só deve atuar na defesa de bens jurídicos relevantes e imprescindíveis para a paz social e que não podem ser protegidos de maneira eficiente de forma menos gravosa. O Direito Penal deve ser a ultima ratio.

Tal Princípio é decorrente da Política Criminal, restritiva ao ius puniendi do Estado, para que não haja uma inflação penal, com sanções penais para um sem número de condutas irrelevantes, fazendo apenas com que o Direito Penal torne-se simbólico e ineficaz. Não se trata da criação intencional de lacunas, mas de impedir uma exagerada produção legiferante, criando uma tutela punitiva penal exagerada.

Desse Princípio decorre o princípio da fragmentariedade, segundo o qual o Direito Penal apenas se atenha a uma tutela seletiva de defesa de bens jurídicos relevantes e da intensidade e gravidade da sua lesão. Nas palavras de Luiz Regis Prado: esse Princípio impõe que o Direito Penal seja um arquipélago de pequenas ilhas, em um mar do penalmente indiferente.

VIII. Princípio da Pessoalidade e da individualização da pena

Pelo Princípio da Pessoalidade, nenhuma pena passará da pessoa do condenado, sendo vedada a punição por fato alheio.

De acordo com o Princípio da Individualização da Pena, deve haver uma justa medida de equilíbrio, entre a norma abstrata apresentada pelo Legislador e o fato concreto julgado pelo Magistrado. Justa medida entre a gravidade do fato efetivamente praticado e a sanção decorrente. A pena deve ser proporcional, razoável e adequada à magnitude da lesão ao bem jurídico de que se constitui o delito. 
IX. Princípio da Proporcionalidade

O Princípio da Proporcionalidade põe em estreita relação a Política Criminal e o Direito Penal. Para Beccaria, "as leis precisam ser proporcionais ao delito e ao dano social causado". Compõem o conceito da Proporcionalidade, a adequação, a necessidade e a proporção propriamente dita. A Necessidade decorre da Fragmentariedade, ou seja, se a medida não pode ser equacionada por outros institutos do Direito que não o Penal, apenas a ser utilizado como ultima ratio. A Adequação diz respeito ao valor estabelecido pela Política Criminal, em seu conjunto de bens jurídicos a serem protegidos e que a medida está de acordo para a consecução da finalidade por ela pretendida. Por fim, a proporcionalidade propriamente dita representa uma ponderação valorativa entre a gravidade do ilícito, a efetiva lesão a um bem jurídico relevante, e a gravidade da pena, constituindo-se uma verdadeira condição de legalidade.

No dizer de Hassemer, citado por Luiz Regis Prado: a exigência de proporcionalidade deve ser determinada mediante um juízo de ponderação entre a carga coativa da pena e o fim perseguido pela cominação penal.

\section{Princípio da Adequação Social}

A Teoria da Adequação Social estabelece que, apesar de uma conduta corresponder integralmente à sua tipificação legal não será considerada típica, se for aceita, adequada e reconhecida socialmente naquele momento histórico-socio-cultural de uma comunidade. Hans Welzel, propositor do Princípio alerta: as condutas socialmente adequadas não são necessariamente exemplares, senão que se mantêm dentro dos marcos da liberdade de ação social. ${ }^{13}$

A concordância ao Direito refere-se às determinações jurídicas de condutas já estabelecidas (por exemplo, o ilícito lesão corporal), enquanto que a adequação faz referência a concepções extra-jurídicas (por exemplo, a prática desportiva, a atuação médico-cirúrgica).

\section{Princípio da Insignificância}

Formulado e proposto por Claus Roxin, decorre do brocardo mínima non curat praetor. É uma manifestação contrária ao uso excessivo da sanção criminal e decorrência de Política Criminal de descriminalização de fatos irrelevantes para que atinjam a dignidade penal e o ius puniendi estatal. A irrelevante ou nenhuma lesão ao bem jurídico protegido não justifica a imposição de uma pena. Muito embora a conduta

13 PRADO, Luiz Regis. Curso de direito penal brasileira: parte geral. 5. ed. São Paulo: Revista dos Tribunais, 2005. v. 1. 
ilícita preencha formal e materialmente o tipo penal, caberá ao Magistrado o recurso de interpretação restritiva, tornando a conduta atípica, dado ser ínfima a lesão ao bem jurídico protegido.

Depreende-se que o Princípio da Intervenção Mínima é dirigido ao Legislador, enquanto o Princípio da Insignificância dirige-se ao Magistrado.

5. O entendimento da doutrina brasileira sobre o Princípio da Insignificância

Segundo o Princípio da Insignificância, é necessária uma efetiva proporcionalidade entre a gravidade da conduta que se pretende punir e a drasticidade da intervenção penal. Frequentemente, condutas que se amoldam a determinado tipo penal, sob o ponto de vista formal, não apresentam nenhuma relevância material. Nessas circunstâncias, pode-se afastar liminarmente a tipicidade penal porque em verdade o bem jurídico não chegou a ser lesado.

A insignificância de determinada conduta deve ser aferida não apenas em relação à importância do bem jurídico atingido, mas especialmente em relação ao grau de intensidade, isto é, pela extensão da lesão produzida. Porém, essa insignificância só pode ser valorada por meio da consideração global da ordem jurídica. ${ }^{14}$

Relacionado com o axioma mínima non curat praetor, Claus Roxin formula o Princípio da Insignificância, como uma manifestação contrária ao uso excessivo da sanção criminal. Por ele, devem ser tidas como atípicas as ações ou omissões que afetem minimamente um bem jurídico penal. A irrelevante lesão do bem jurídico protegido não justifica a imposição de uma pena, devendo-se excluir a tipicidade em casos de danos de pouca importância, monta ou relevância. É um critério de interpretação restritiva (correção típica) e como critério para a determinação do injusto penal. Convém advertir para a grande imprecisão desse critério, o que pode atingir gravemente a segurança jurídica. ${ }^{15}$

O tipo legal é a manifestação de uma norma que é gerada para tutelar a relação de um sujeito com um ente, chamado bem jurídico. A norma proibitiva que dá lugar ao tipo não está isolada, mas permanece junto com outras normas também proibitivas, formando uma ordem normativa, onde não se concebe que uma norma proíba o que outra ordena ou aquela que outra fomenta. Se isso fosse admitido, não se poderia falar de ordem normativa e sim de um amontoado caprichoso de normas arbitrariamente reunidas.

O fenômeno da fórmula legal pode aparentemente abarcar hipóteses que não são alcançadas pela norma proibitiva, considerada isoladamente, mas que, de modo algum, podem incluir-se na sua proibição, quando considerada conglobadamente, isto é,

14 BITTENCOURT, Cezar Roberto; CONDE, Francisco Muñoz. Teoria geral do delito. 2. ed. São Paulo: Saraiva, 2004.

15 PRADO, Luiz Regis. Curso de direito penal brasileira: parte geral. 5. ed. São Paulo: Revista dos Tribunais, 2005. v. 1. 
fazendo parte de um universo ordenado de normas. Daí que a tipicidade penal não se reduz à tipicidade legal, a adequação à norma legal, mas sim que deva evidenciar uma verdadeira proibição com relevância penal. Para isso é necessário que esteja proibida à luz da consideração conglobada da norma. Isto significa que a tipicidade penal implica a tipicidade legal corrigida pela tipicidade conglobante, que pode reduzir o âmbito da proibição aparente, que surge da consideração isolada da tipicidade legal. ${ }^{16}$

A insignificância da afetação do bem jurídico exclui a tipicidade, mas só pode ser estabelecida através da consideração conglobada da norma: toda ordem normativa persegue uma finalidade, tem um sentido, que é a garantia jurídica, fim primordial de uma Política Criminal. A insignificância só pode surgir à luz da finalidade geral que dá sentido à ordem normativa, e, portanto, à norma em particular, e que nos indica que essas hipóteses estão excluídas de seu âmbito de proibição, o que não pode ser estabelecido à luz de sua consideração isolada.

Porém, nem sempre é possível determinar de plano o caráter bagatelar de uma conduta, o que acontece amiúde em casos de descaminho, crimes previdenciários e de sonegação de impostos. É notório que o furto de um desodorante é conduta insignificante, mas o que dizer de um descaminho em que os produtos têm o valor total de $\mathrm{R} \$ 1.000,00$ ou R \$ 2.000,00 ou da sonegação de R \$ 500,00 de impostos? O que seria, nesses casos, lesão significativa ao bem jurídico protegido?

Para responder a essa questão, torna-se necessário recorrer a uma decorrência lógica do princípio da fragmentariedade: o caráter subsidiário do sistema penal. De acordo com essa característica, o Direito Penal só deve atuar quando a ação dos outros ramos do ordenamento jurídico se mostrar ineficaz e insuficiente para a repressão do comportamento considerado indesejável. Sendo essa atuação suficiente a eventual resposta penal a essa conduta se torna desnecessária e desproporcional.

Nesse sentido e considerando o caráter fragmentário do Direito como um todo, vemos ocasiões em que mesmo os outros ramos do ordenamento jurídico, que não contém toda a carga sancionatória do Direito Penal, furtam-se a atuar, frente ao exíguo dano aos bens jurídicos tutelados. Nestes casos, a atuação estatal, além dos já citados problemas, incorreria em grave ofensa ao princípio da eficiência, já que o dispêndio de recursos materiais e humanos seria claramente desproporcional ao ganho que se poderia obter. Portanto, o caso não é só de coerência jurídica, mas também de compreender, realisticamente, as necessidades e as limitações da práxis estatal.

Assim, encontramos em nosso ordenamento jurídico normas segundo as quais o Estado, pelas razões já expostas, se abdica a reprimir certas condutas que, em face de seu valor, se tornam irrelevantes. Ocorre desse modo na Procuradoria da Fazenda

16 ZAFFARONI, Eugenio Raúl; PIERANGELI, José Herinque. Manual de direito penal brasileiro: parte geral. 5. ed. rev. e atual. São Paulo: Revista dos Tribunais, 2004. 
Nacional que, de acordo com a lei, está desobrigada de impetrar ações de cobrança de débitos inferiores a R\$1.000,00. Já na Procuradoria do Instituto Nacional de Seguridade Social (INSS) esse limite é de R\$ 5.000,00. Ora, se os Direitos Tributário e Previdenciário, que contam com sanções rigorosas, mas, que de qualquer forma são bem mais suaves que as penas criminais, consideram desnecessária a persecução do autor, o que dirá o Direito Penal, que, como visto, deve agir somente em ultima ratio?

A tipicidade penal é formada pela tipicidade legal (subsunção da conduta à norma descrita no tipo penal) e a tipicidade conglobante (antinormatividade). $\mathrm{Na}$ falta de uma, atípico será o fato e, consequentemente, irrelevante para o Direito penal. O Princípio da Insignificância reduz o âmbito de proibição da tipicidade legal (aquele de pura e simples subsunção), além de se chocar com a tipicidade conglobante (antinormatividade). Consequentemente, torna atípico o fato na seara penal, em que pese haver lesão a bem juridicamente protegido pela norma penal, pela sua pouca gravidade ou intensidade. ${ }^{10}$ Zaffaroni e Pierangeli

A interpretação com base em critérios absolutos não é admissível no campo do Direito, ciência de natureza social, que lida com valores humanos e que não pode ser interpretada de modo inflexível. A tipicidade não se esgota no juízo lógico-formal de subsunção do fato ao tipo legal de crime. A ação descrita tipicamente deve revelar-se, ainda, ofensiva ou perigosa para os bens jurídicos protegidos pela lei penal.

O princípio da insignificância impõe-se, justamente, para evitar que a norma edificada abranja os casos leves, adequando-a aos princípios fundamentais do Direito Penal, atuando como elemento de interpretação restritiva do tipo.

O fundamento do Princípio da Insignificância está, também, na ideia de proporcionalidade que a pena deve guardar em relação à gravidade do crime. Nos casos de ínfima afetação ao bem jurídico, o conteúdo do injusto é tão pequeno que não subsiste nenhuma razão para o pathos ético da pena, de sorte que a mínima pena aplicada seria desproporcional à significação social do fato. ${ }^{17}$

A principal finalidade legitimadora da pena na atualidade e na visão do idealizador do funcionalismo teleológico, Claus Roxin, é a prevenção geral de integração, ou positiva, que busca assegurar a confiança da população na vigência fática das normas e dos bens jurídicos tutelados por estas na Política Criminal.

Ocorre que os valores político-criminais concernentes aos fins da pena foram devidamente posicionados pelos funcionalistas, no juízo de culpabilidade. Em razão disso, tornou-se inviável a realização de ponderações entre os mencionados valores e o implementado pelo Princípio da Insignificância, este verificado no juízo de tipicidade.

17 SANGUINÉ, Odone. Observações sobre o princípio da insignificância. Fascículos de Ciências Penais, Porto Alegre, v. 3, n. 1, p. 36-50, jan./mar. 1990. 
Segundo o Princípio da Insignificância, que se revela por inteiro pela sua própria denominação, o direito penal, por sua natureza fragmentária, só vai até onde seja necessário para a proteção do bem jurídico. Não deve ocupar-se de bagatelas. Assim, no sistema penal brasileiro, o dano do art. 163 do Código Penal não deve ser qualquer lesão à coisa alheia, mas sim aquela que possa representar prejuízo de alguma significação para o proprietário da coisa; o descaminho do art. 334 , parágrafo $1^{\circ}, \mathrm{d}$, não será certamente a posse de pequena quantidade de produto estrangeiro, de valor reduzido, mas sim a de mercadoria cuja quantidade ou cujo valor indique lesão tributária, de certa expressão, para o Fisco; o peculato do art. 312 não pode estar dirigido para ninharias como a que vimos em um volumoso processo no qual se acusava antigo servidor público de ter cometido peculato consistente no desvio de algumas poucas amostras de amêndoas; a injúria, a difamação e a calúnia dos arts. 140, 139 e 138, devem igualmente restringir-se a fatos que realmente possam afetar significativamente a dignidade, a reputação, a honra, o que exclui ofensas tartamudeadas e sem consequências palpáveis. ${ }^{18}$

$\mathrm{Na}$ realidade, e considerados, de um lado, o Princípio da Intervenção Penal Mínima do Estado, que tem por destinatário o próprio Legislador, e, de outro, o Princípio da Insignificância, que se dirige ao magistrado, na condição de aplicador da lei penal ao caso concreto, cumpre reconhecer que o Direito Penal não se deve ocupar de condutas que não importem em lesão significativa a bens jurídicos tutelados, seja ao titular do bem jurídico tutelado, seja à integridade da própria ordem social. ${ }^{19}$

O Princípio da bagatela ou da Insignificância não tem previsão legal no direito brasileiro, sendo considerado, contudo, princípio auxiliar de determinação da tipicidade, sob a ótica da objetividade jurídica. Funda-se no brocardo civil minimis non curat praetor e na conveniência da Política Criminal. Se a finalidade do tipo penal é tutelar um bem jurídico quando a lesão, de tão insignificante, torna-se imperceptível, não será possível proceder a seu enquadramento típico, por absoluta falta de correspondência entre o fato narrado na lei e o comportamento iníquo realizado. É que, no tipo, somente estão descritos os comportamentos capazes de ofender o bem jurídico tutelado pela norma. Por essa razão, os danos de nenhuma monta devem ser considerados atípicos. A tipicidade penal reclama ofensa de certa gravidade exercida sobre os bens jurídicos, pois nem sempre ofensa mínima a um bem ou interesse juridicamente protegido é capaz de se incluir no requerimento reclamado pela tipicidade penal, o qual exige ofensa de alguma magnitude a esse mesmo bem jurídico. $^{20}$

\footnotetext{
18 TOLEDO, Francisco de Assis. Princípios básicos do direito penal. 3. ed. São Paulo: Saraiva, 2002.

19 DOTTI, René Ariel. Curso de direito penal: parte geral. São Paulo: Saraiva, 2004.

20 CAPEZ, Fernando. Direito penal: parte geral. São Paulo: Saraiva, 2004.
} 
6. Jurisprudência

A seguir serão apresentados julgados envolvendo a aplicação ou não do Princípio da Insignificância.

Esse acórdão foi o primeiro a mencionar os elementos necessários à descaracterização do delito como atípico, sendo interpretado sob a luz do Princípio da Insignificância. Em sua fundamentação apresenta os requisitos necessários para que seja aplicado o Princípio da Insignificância.

\section{HC 84412 / SP - SÃO PAULO ${ }^{21}$ \\ Relator(a): Min. CELSO DE MELLO \\ Julgamento: 19/10/2004 Órgão Julgador: Segunda Turma \\ E M E N T A: PRINCÍPIO DA INSIGNIFICÂNCIA - IDENTIFICAÇÃO DOS VETORES CUJA PRESENÇA LEGITIMA O RECONHECIMENTO DESSE POSTULADO DE POLÍTICA CRIMINAL - CONSEQÜENTE DESCARACTERIZAÇÃO DA TIPICIDADE PENAL EM SEU ASPECTO MATERIAL - DELITO DE FURTO - CONDENAÇÃO IMPOSTA A JOVEM DESEMPREGADO, COM APENAS 19 ANOS DE IDADE - "RES FURTIVA" NO VALOR DE R\$ 25,00 (EQUIVALENTE A 9,61\% DO SALÁRIO MÍNIMO ATUALMENTE EM VIGOR) - DOUTRINA - CONSIDERAÇÕES EM TORNO DA JURISPRUDÊNCIA DO STF - PEDIDO DEFERIDO. O PRINCÍPIO DA INSIGNIFICÂNCIA QUALIFICA- SE COMO FATOR DE DESCARACTERIZAÇÃO MATERIAL DA TIPICIDADE PENAL.}

O princípio da insignificância - que deve ser analisado em conexão com os postulados da fragmentariedade e da intervenção mínima do Estado em matéria penal - tem o sentido de excluir ou de afastar a própria tipicidade penal, examinada na perspectiva de seu caráter material. Doutrina. Tal postulado - que considera necessária, na aferição do relevo material da tipicidade penal, a presença de certos vetores, tais como

(a) a mínima ofensividade da conduta do agente,

(b) a nenhuma periculosidade social da ação,

(c) o reduzidíssimo grau de reprovabilidade do comportamento e

(d) a inexpressividade da lesão jurídica provocada apoiou-se, em seu processo de formulação teórica, no

${ }_{21}$ http://www.stf.jus.br/portal/jurisprudencia. 
reconhecimento de que o caráter subsidiário do sistema penal reclama e impõe, em função dos próprios objetivos por ele visados, a intervenção mínima do Poder Público.

O Postulado da Insignificância e a função do Direito Penal: minimis non curat praetor. O sistema jurídico há de considerar a relevantíssima circunstância de que a privação da liberdade e a restrição de direitos do indivíduo somente se justificam quando estritamente necessárias à própria proteção das pessoas, da sociedade e de outros bens jurídicos que lhes sejam essenciais, notadamente naqueles casos em que os valores penalmente tutelados se exponham a dano, efetivo ou potencial, impregnado de significativa lesividade. O direito penal não se deve ocupar de condutas que produzam resultado, cujo desvalor - por não importar em lesão significativa a bens jurídicos relevantes - não represente, por isso mesmo, prejuízo importante, seja ao titular do bem jurídico tutelado, seja à integridade da própria ordem social.

Decisão: a Turma, por votação unânime, deferiu o pedido de "habeas corpus" e, com fundamento no princípio da insignificância, invalidou a condenação penal imposta ao ora paciente, determinando, em consequência, a extinção definitiva do procedimento penal que contra ele foi instaurado (Processo-crime n. 238/2000-1 ${ }^{\text {a }}$ Vara Criminal da comarca de Barretos/SP), nos termos e para os fins indicados no voto do Relator.

II. $\mathrm{STJ}^{22}$

Recurso Especial n. 1.060.971-RS (2008/0114688-3)

Relator: Ministro Felix Fischer

PENAL E PROCESSUAL PENAL. RECURSO ESPECIAL. FURTO. PRINCÍPIO DA INSIGNIFICÂNCIA.

I - No caso do furto, para efeito da aplicação do Princípio da Insignificância é imprescindível a distinção entre ínfimo (ninharia) e pequeno valor. Este, ex vi legis, implica eventualmente em furto privilegiado; aquele, na atipia conglobante (dada a mínima gravidade)

II - A interpretação deve considerar o bem jurídico tutelado e o tipo de injusto.

III - In casu, trata-se de furto de um facão, duas facas, duas folhas de facão, dois freios para cavalo com corda, uma manivela com pua, um par de sapatos do tipo botina, uma japona e duas toalhas, avaliados conjuntamente em R \$ 87,00 afasta, assim, a aplicação do Princípio da Insignificância.

22 https://www2.stj.jus.br/revistaeletronica/ita.asp?registro=200801146883\&dt_publicacao=03/11/2008. 
Por esse julgado do STJ pode-se observar que, em delitos patrimoniais torna-se bastante difícil estabelecer o que seja insignificância. Por essa razão mais se firma a doutrina e a jurisprudência que a aplicação ou não somente pode ser feita em casos concretos. Nesse caso, apesar de o valor total poder ser considerado insignificante, foi levado em conta que o furto foi de inúmeros itens, que poderiam servir ao possuidor para, por exemplo, realizar trabalhos para a sua subsistência.

III - STJ 23
Habeas Corpus 178.178 - Quinta Turma - Relator
Ministro Napoleão Nunes Maia - 25.11.2010. Tentativa
de furto qualificado. Res furtiva: peça de picanha e
mouse, avaliados em R\$ 64,60. Incidência do Princípio
da Insignificância. Precedentes do STJ e do STF. Parecer
do MPF pela concessão do Writ. Ordem concedida para
declarar atípica a conduta praticada, com consequente
trancamento da ação penal.

O princípio da insignificância, que está diretamente ligado aos postulados da fragmentariedade e intervenção mínima do Estado em matéria penal, tem sido acolhido pelo magistério doutrinário e jurisprudencial tanto desta Corte, quanto do colendo Supremo Tribunal Federal, como causa supralegal de exclusão de tipicidade. Vale dizer, uma conduta que se subsuma perfeitamente ao modelo abstrato previsto na legislação penal pode vir a ser considerada atípica por força deste postulado.

Verificada a excludente de aplicação da pena, por motivo de política criminal, é imprescindível que a sua aplicação se dê de forma prudente e criteriosa, razão pela qual é necessária a presença de certos elementos, tais como (a) a mínima ofensividade da conduta do agente; (b) a ausência total de periculosidade social da ação; (c) o ínfimo grau de reprovabilidade do comportamento e (d) a inexpressividade da lesão jurídica ocasionada, consoante já assentado pelo colendo Pretório Excelso (HC 84.412/SP, Rel. Min. Celso de Mello, DJU 19.04.2004).

Tem-se que o valor do bem furtado pelo paciente, além de ser ínfimo, não afetou de forma expressiva o patrimônio da vítima, razão pela qual incide na espécie o Princípio da Insignificância, reconhecendo-se a inexistência do crime de furto pela exclusão da tipicidade material.

Ordem concedida para, aplicando o princípio da insignificância, declarar atípica a conduta praticada, com o consequente trancamento da Ação Penal.

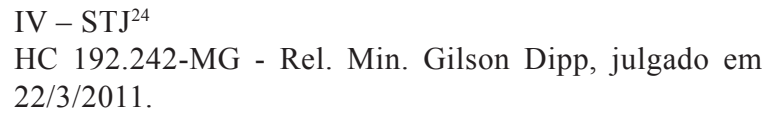

$23 \mathrm{https}: / / \mathrm{www}$.stj.jus.br/revistaeletronica/ita.asp?registro=2010012262093\&dt_publicacao=13/12/2010.

24 http://www.stj.jus.br/SCON/infojur/doc.jsp. 
PRINCÍPIO. INSIGNIFICÂNCIA. POLICIAL.

O paciente, policial militar, fardado e em serviço, subtraiu uma caixa de bombons de um supermercado, colocando-a dentro de seu colete à prova de balas. Vê-se, assim, não ser possível aplicar o Princípio da Insignificância à hipótese, visto não estarem presentes todos os requisitos necessários para tal (mínima ofensividade da conduta, nenhuma periculosidade social da ação, reduzidíssimo grau de reprovação do comportamento e inexpressividade da lesão jurídica provocada).

Apesar de poder tachar de inexpressiva a lesão jurídica em razão de ser ínfimo o valor dos bens subtraídos ( $\mathrm{R} \$ 0,40)$, há alto grau de reprovação na conduta do paciente, além de ela ser relevante para o Direito Penal; pois, aos olhos da sociedade, o policial militar representa confiança e segurança, dele se exige um comportamento adequado, dentro do que ela considera correto do ponto de vista ético e moral.

Anote-se que a interpretação que se dá ao art. 240, § $1^{\circ}$, do CPM (que ao ver do paciente justificaria a aplicação do referido princípio) não denota meio de trancar a ação penal, mas sim que cabe ao juízo da causa, após o processamento dela, analisar se a infração pode ser considerada apenas como disciplinar. Precedentes citados do STF: HC 84.412-0-SP,

$\mathrm{V}-\mathrm{STJ}^{25}$

Habeas corpus RHC 27039

Relator - Ministro OG Fernandes

RECURSO ORDINÁRIO NO HABEAS CORPUS. MOEDA FALSA. APREENSÃO DE VINTE CÉDULAS DE R\$ 10,00. APLICAÇÃO DO PRINCÍPIO DA INSIGNIFICÃNCIA. IMPOSSIBILIDADE. PRISÃO PREVENTIVA. AUSÊNCIA DOS REQUISITOS DO ART. 312 DO CPP. SUPERVENIÊNCIA DE SENTENÇA CONDENATÓRIA. QUESTÃO PREJUDICADA.

1. Segundo iterativa jurisprudência desta Corte, o Princípio da Insignificância não se aplica ao delito de moeda falsa, uma vez que o bem jurídico tutelado pelo art. 289 do Código Penal é a fé pública, insuscetível de ser mensurada pelo valor e quantidade de cédulas falsas apreendidas.

2. não descrito

3. Ainda que assim fosse, quantidade de cédulas apreendidas em poder do recorrente, vinte notas de R\$ 10,00 , somadas atingem $R \$ 200,00$, o que não pode ser considerado ínfimo.

25 https://www2.stj.jus.br/revistaeletronica/Abre_Documento.asp?sLink=ATC\&sSeq=14465888\&sReg=2009 02081771\&sData $=20110404 \&$ sTipo $=5 \&$ formato $=$ PDF. 
$\mathrm{VI}-\mathrm{STF}^{26}$

HC 97772 / RS - RIO GRANDE DO SUL

HABEAS CORPUS

Relator(a): Min. CÁRMEN LÚCIA

Julgamento: 03/11/2009 Órgão Julgador: Primeira

Turma

EMENTA: HABEAS CORPUS. PENAL. TENTATIVA

DE FURTO. ALEGAÇÃO DE INCIDÊNCIA DO PRINCÍPIODAINSIGNIFICÂNCIA: INVIABILIDADE. VIOLAÇÃO DE DOMICÍLIO. REINCIDÊNCIA. HABEAS CORPUS DENEGADO.

1. A tipicidade penal não pode ser percebida como o trivial exercício de adequação do fato concreto à norma abstrata. Além da correspondência formal, para a configuração da tipicidade, é necessária uma análise materialmente valorativa das circunstâncias do caso concreto, no sentido de se verificar a ocorrência de alguma lesão grave, contundente e penalmente relevante do bem jurídico tutelado.

2. O Princípio da Insignificância reduz o âmbito de proibição aparente da tipicidade legal e, por consequência, torna atípico o fato na seara penal, apesar de haver lesão a bem juridicamente tutelado pela norma penal.

3. Para a incidência do Princípio da Insignificância, devem ser relevados o valor do objeto do crime e os aspectos objetivos do fato - tais como a mínima ofensividade da conduta do agente, a ausência de periculosidade social da ação, o reduzido grau de reprovabilidade do comportamento e a inexpressividade da lesão jurídica causada.

4. No caso dos autos, em que o delito foi praticado com a invasão do domicílio da vítima, não é de se desconhecer o alto grau de reprovabilidade do comportamento do Paciente.

5. A reincidência, apesar de tratar-se de critério subjetivo, remete a critério objetivo e deve ser excepcionada da regra para análise do princípio da insignificância, já que não está sujeita a interpretações doutrinárias e jurisprudenciais ou a análises discricionárias. O criminoso reincidente apresenta comportamento reprovável, e sua conduta deve ser considerada materialmente típica.

6. Ordem denegada.

26 https://www.stf.jus.br/portal/jurisprudencia/listarJurisprudencia.asp?s1=Habeas+corpus+\%2897772. NUME. + OU+97772. ACMS\%base=baseAcordaos 
6. O Princípio da Insignificância nos julgados em Direito Tributário

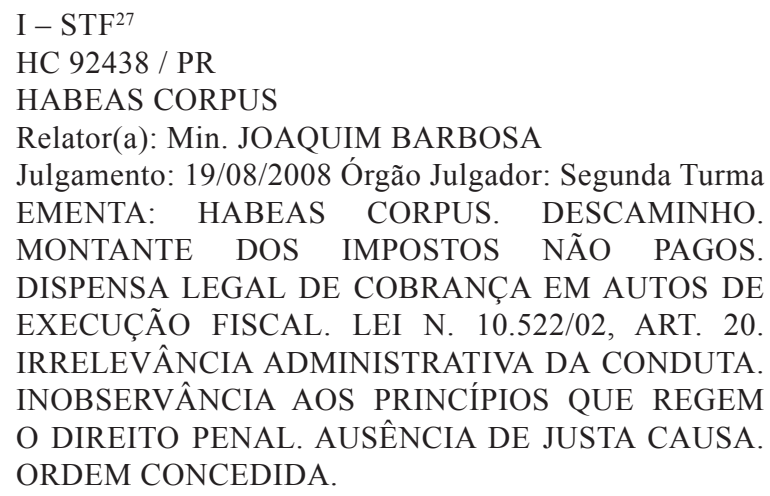

1. De acordo com o artigo 20 da Lei n. 10.522/02, na redação dada pela Lei $\mathrm{n}^{\circ} 11.033 / 04$, os autos das execuções fiscais de débitos inferiores a dez mil reais serão arquivados, sem baixa na distribuição, mediante requerimento do Procurador da Fazenda Nacional, em ato administrativo vinculado, regido pelo princípio da legalidade.

2. O montante de impostos supostamente devido pelo paciente é inferior ao mínimo legalmente estabelecido para a execução fiscal, não constando da denúncia a referência a outros débitos em seu desfavor, em possível continuidade delitiva.

3. Ausência, na hipótese, de justa causa para a ação penal, pois uma conduta administrativamente irrelevante não pode ter relevância criminal. Princípios da subsidiariedade, da fragmentariedade, da necessidade e da intervenção mínima que regem o Direito Penal. Inexistência de lesão ao bem jurídico penalmente tutelado.

4. O afastamento, pelo órgão fracionário do Tribunal Regional Federal da $4^{\mathrm{a}}$ Região, da incidência de norma prevista em lei federal aplicável à hipótese concreta, com base no art. 37 da Constituição da República, viola a cláusula de reserva de plenário. Súmula Vinculante $\mathrm{n}^{\circ} 10$ do Supremo Tribunal Federal. 5. Ordem concedida, para determinar o trancamento da ação penal.

27 https://www.stf.jus.br/portal/jurisprudencia/listarJurisprudencia.asp?s 1=Habeas + corpus $+\% 2892438$. NUME.+OU+.ACMS\%29\%base=baseAcordos 
Decisão
Concedida a ordem. Votação unânime. Ausentes,
justificadamente, neste julgamento, os Senhores Ministros
Celso
de Mello e Ellen Gracie. Presidiu, este julgamento, o
Senhor
Ministro Cezar Peluso. $2^{\text {a }}$ Turma, 19.08.2008.
II - STF ${ }^{28}$
Habeas Corpus 92.408- PR
Min. Cármem Lúcia
EMENTA. HABEAS CORPUS. PENALEPROCESSUAL
PENAL. TRANCAMENTO DA AÇÃO PENAL.
PACIENTE CONDENADO PELA INFRAÇÃO DO ART.
334, CAPUT, DO CÓDIGO PENAL (DESCAMINHO).
ALEGAÇÃO DE INCIDÊNCIA DO PRINCÍPIO DA
INSIGNIFICÂNCIA. EXISTÊNCIA DE PRECEDENTE
DESTE SUPREMO TRIBUNAL FAVORÁVEL À TESE
DE IMPETRAÇÃO. HABEAS CORPUS DEFERIDO
PARA DETERMINAR O TRANCAMENTO DA AÇÃO
PENAL.

III $-\mathrm{STF}^{29}$

HABEAS CORPUS 100.513 - SP

Relatora: Min Ellen Grace

DIREITO PENAL. HABEAS CORPUS. CRIME DE DESCAMINHO. PRINCÍPIO DA INSIGNIFICÂNCIA. APLICABILIDADE. VALOR SONEGADO INFERIOR AO FIXADO NO ART. 20 DA LEI 10.522/02. ATIPICIDADE DE CONDUTA. RELATIVIZAÇÃO , IN CASU, DA SÚMULA 691 DO STF. ORDEM CONCEDIDA DE OFÍCIO.

IV - Julgados do Conselho de Recursos do Sistema Financeiro Nacional (CRSFN): ${ }^{30}$

Recurso 3470 - Processo origem BCB 9900986656 RECURSO DE OFÍCIO

RECORRENTE: BANCO CENTRAL DO BRASIL RECORRIDO: ARI PINTO PORTUGAL

EMENTA: RECURSO DE OFÍCIO - Câmbio Importação - Falsa declaração prestada em contrato - Ingresso das mercadorias no País - Valor inferior Princípio da Insignificância - Recurso improvido.

\footnotetext{
28 http://redir.stf.jus.br/paginadorpub/paginador.jsp?docTP=AC\%docID $=516845$

29 http://redir.stf.jus.br/paginadorpub/paginador.jsp?docTP=AC\%docID $=610070$

30 http://www4.bcb.gov.br/NXT/gateway.dll?f=templates\&fn=default.htm\&vid=nmsSecreCRSFN:idvSecreC RFN
} 
ACÓRDÃO/CRSFN 3310/01: Vistos, relatados e discutidos os presentes autos, decidem os membros do Conselho de Recursos do Sistema Financeiro Nacional, por unanimidade, negar provimento ao recurso de ofício interposto, mantida a decisão do órgão de primeiro grau no sentido de arquivar o processo em relação ao recorrido, sr. ....., não devendo ser considerada, por insignificante, a diferença existente entre o valor do contrato e o das mercadorias de fato adquiridas ao vendedor no estrangeiro.

V - ACÓRDÃO/CRSFN 3545/02 - Recurso 3760 Processo BCB $9900968212^{31}$

Recurso de Ofício - $210^{\mathrm{a}}$ Sessão em 27 de fevereiro de 2002

Recorrente: Banco Central do Brasil

Recorrida: U.... S.A.-MASSA FALIDA

EMENTA: Recurso de Ofício - Câmbio - Exportação - Falta de negociação das divisas em estabelecimento autorizado a operar na modalidade ou de repatriamento das mercadorias - Princípio da Insignificância - Sonegação de cobertura não demonstrada - Recurso improvido.

Vistos, relatados e discutidos os presentes autos, decidem os membros do Conselho de Recursos do Sistema Financeiro Nacional, por unanimidade, negar provimento ao recurso de ofício interposto, mantida a decisão do órgão de primeiro grau no sentido de arquivar o processo em relação à recorrida, U.........S.A. - MASSA FALIDA, à vista do reduzido valor da pendência cambial em face do montante das operações em causa, o que dá azo à aplicação do Princípio da Insignificância.

\section{Conclusão}

O Princípio da Insignificância constitui-se em um elemento auxiliar da interpretação restritiva a ser elaborada pelo Magistrado, fundamental para o Direito Penal, e que torna o fato penalmente atípico, muito embora no fato in concreto seja formal e materialmente típico. Pela insignificância no aspecto material, há irrelevância ou mesmo inexistência de lesão ao bem jurídico considerado.

A sua aplicação decorre de Política Criminal estabelecendo o princípio de Intervenção Mínima do Estado estatuída constitucionalmente, reservando ao Direito Penal em seu poder punitivo resguardar bens jurídicos apenas de lesões relevantes. 31 http://www4.bcb.gov.br/NXT/gateway.dll?f=templates\&fn=default.htm\&vid=nmsSecreCRSFN:idvSecreC
RFN 
Por se tratar de um Princípio, não é positivado, sendo apenas um elemento a mais de interpretação do fato in concreto. Sua aplicação não afasta a de outros elementos valorativos, como é o caso do art. 59 do Código Penal.

Por esse motivo, não há, em sua utilização, qualquer lesão à segurança jurídica, por não ser norma positivada, conforme doutrina minoritária argumenta. A segurança jurídica decorre da aplicação legal do funcionalismo sistêmico de todo o ordenamento, que inclui também os Princípios Gerais do Direito, ao qual pertence o Princípio da Insignificância, que a Constituição eleva como fundamentais para o Estado Democrático de Direito.

O Supremo Tribunal Federal já estabeleceu em julgado os critérios a serem considerados para a aceitação do Princípio da Insignificância como fundamentação para a atipicidade.

Segundo o entendimento depreendido, apresenta-se como errônea a fundamentação de atipicidade e extinção processual nos casos apresentados de Direito Tributário em decorrência do Princípio da Insignificância.

A disponibilidade de bens públicos decorre exclusivamente de lei expressa para tanto e não se encontra no âmbito do poder discricionário do Magistrado. O Legislador pode ter se utilizado dele para fazer valer o Princípio de Intervenção Mínima do Estado, ao legislar positivamente, estabelecendo valores mínimos para que haja a persecução penal. Portanto, se há uma norma estatuindo que abaixo de determinado valor não há a persecução penal, a fundamentação é a própria norma, e não o Princípio da Insignificância.

São Paulo, junho de 2012.

Referências

BECCARIA, Cesare. Dos delitos e das penas. Ed. Hemus, 1983

BITENCOURT, Cezar Roberto; CONDE, Francisco Muñoz. Teoria geral do delito. 2. ed. São Paulo: Saraiva, 2004.

CAPEZ, Fernando. Direito penal: parte geral. São Paulo: Saraiva, 2004.

DOTTI, René Ariel. Curso de direito penal: parte geral. 2. ed. Rio de Janeiro: Forense, 2004.

GILIOLI, Adolfo Lemes. Academia e discursos acadêmicos. São Paulo: Ed. Martin Claret, 2001.

GOMES, Luiz Flávio. Norma e bem jurídico no direito penal. São Paulo: Revista dos Tribunais, 2002 . 
KELSEN, Hans. Teoria pura do direito. Trad. João Baptista Machado. 6 ed. São Paulo: Martins Fontes, 2005.

PEREZ LUÑO, A. E. Derechos humanos, Estado de derecho y Constituición. 1. ed. Madrid: Tecnos, 1990.

PRADO, Luiz Regis. Curso de direito penal brasileiro: parte geral. 5. ed. São Paulo: Revista dos Tribunais, 2005. v. 1.

REALE, Miguel. Lições preliminares de direito. 25. ed. São Paulo: Saraiva, 2000.

ROXIN, Claus, Politica Cruminal y sistema del derecho penal. Trad. Francisco Muñoz Conde y Eugenio R. Zaffaroni. 2. ed. Buenos Aires: Ed. Hammurabi, 2002.

SANGUINÉ, Odone. Observações sobre o princípio da insignificância. Fascículos de Ciências Penais, Porto Alegre, v. 3, n. 1, p. 36-50, jan./mar. 1990.

TOLEDO, Francisco de Assis. Princípios básicos do direito penal. 3. ed. São Paulo: Saraiva, 2002. VITOR HUGO. Os miseráveis. São Paulo: Ed. Clube do Livro, 1958.

ZAFFARONI, Eugenio Raúl; PIERANGELI, José Henrique. Manual de direito penal brasileiro: parte geral. 5. ed. rev. e atual. São Paulo: Revista dos Tribunais, 2004.

WELZEL, HANS. Derecho penal alemã. Trad. Juan Bustos Ramírez e Sérgio Yáñez Pérez. 11. ed. Santiago: Ed. Jurídica, 1970.

\section{Consulta eletrônica - 11.06.2011}

http://www.stf.jus.br/portal/jurisprudencia https://ww2.stj.jus.br/revistaeletronica/ita.asp?registro=200801146883\&dt_publicacao=03/11/2008 https://ww2.stj.jus.br/revistaeletronica/ita.asp?registro=201001226093\&dt_publicacao=13/12/2010 http://www.stj.jus.br/SCON/infojur/doc.jsp

https://ww2.stj.jus.br/revistaeletronica/Abre_Documento.asp?sLink=ATC\&sSeq $=14465888 \&$ sRe $\mathrm{g}=200902081771 \& \mathrm{sData}=20110404 \& \mathrm{sTipo}=5 \&$ formato $=$ PDF

http://www.stf.jus.br/portal/jurisprudencia/listarJurisprudencia.asp?s1=Habeas+corpus+\%2897772. NUME.+OU+97772.ACMS.\%29\&base=baseAcordaos

http://www.stf.jus.br/portal/jurisprudencia/listarJurisprudencia.asp?s1=Habeas+corpus+\%2892438. NUME.+OU+92438.ACMS.\%29\&base=baseAcordaos

http://redir.stf.jus.br/paginadorpub/paginador.jsp?docTP=AC\&docID=516845

http://redir.stf.jus.br/paginadorpub/paginador.jsp?docTP=AC\&docID=610070 
http://www4.bcb.gov.br/NXT/gateway.dll?f=templates\&fn=default.htm\&vid=nmsSecreCRSFN:id vSecreCRSFN

http://www4.bcb.gov.br/NXT/gateway.dll?f=templates\&fn=default.htm\&vid=nmsSecreCRSFN:id vSecreCRSFN 